\title{
A reinvenção da deficiência: novas metáforas na natureza dos corpos ${ }^{\star}$
}

\author{
Bruno Sena Martins $\star \star$ \\ Universidade de Coimbra, Coimbra, Portugal
}

\begin{abstract}
Resumo
O conceito de deficiência tem sido profundamente contestado nas últimas décadas, tanto política como epistemologicamente. Por um lado, está em causa o reconhecimento de que a filiação de determinadas diferenças sob a noção de deficiência constitui uma recente "invenção" da modernidade ocidental. Por outro, trata-se de pulsar as consequências dessa construção para as pessoas marcadas pelo estigma da deficiência. Estabelecendo um diálogo com importantes contribuições da teoria crítica, recrutando noções como "páticas de separação" (Michel Foucault), "materialização" (Judith Butler), "corpo múltiplo" (Annemarie Mol) e "sociologia das ausências" (Boaventura de Santos), o presente artigo procura entender como a noção de deficiência pode ser desmobilizada por leituras insurgentes das hierarquias da modernidade.
\end{abstract}

Palavras-chave: deficiência; Judith Butler; Annemarie Mol; Michel Foucault; Boaventura de Sousa Santos.

\section{The reinvention of disability: new metaphors in the nature of bodies}

\begin{abstract}
The concept of disability has been profoundly challenged in the last decades, both politically and epistemologically. On the one hand, there is the recognition that affiliation of certain differences under the concept of disability is nothing but a recent "invention" of Western modernity. On the other hand, is the assumption of the consequences of that construction for the people labeled as disabled? We establish dialogue with important contributions of critical theory, addressing concepts as "dividing practices" (Michel Foucault), "materialization" (Judith Butler), "the body multiple "(Annemarie Mol) and "sociology of absences" (Boaventura de Sousa Santos), this article attempts understand how the notion of disability can be demobilized by insurgents readings of modernity and its hierarchies.
\end{abstract}

Keywords: disability; Judith Butler; Annemarie Mol; Michel Foucault; Boaventura de Sousa Santos.

\section{"O corpo múltiplo"}

Numa interessante etnografia levada a cabo num hospital holandês, Annemarie Mol (2002) desenvolve uma minuciosa investigação sobre os processos quotidianos de tratamento e cura da arteriosclerose. Percorrendo no mesmo hospital os diversos departamentos em que as práticas médicas se ocupam da arteriosclerose, inquirindo sintomas, medindo, analisando, visualizando, intervindo, Mol verifica como o mesmo corpo é diferentemente performado (enacted). Por exemplo, o corpo considerado na clínica e no laboratório define-se através de discursos e dispositivos diversos e que, por isso, não definem o mesmo objeto:

As práticas de performação [enacting] da arteriosclerose clínica e da arteriosclerose patológica excluem-se mutuamente. As primeiras requerem um paciente que se queixe de dores nas pernas. As segundas requerem uma secção transversal de uma artéria visível no microscópio. Essas exigências são incompatíveis, pelo menos não podem ser realizadas simultaneamente. [...] A incompatibilidade é uma questão prática. É uma questão de pacientes que falam por oposição a partes do corpo que são seccionadas. De falar de dor por oposição a estimar o tamanho das células. De fazer questões por oposição a preparar slides. No ambulatório e no departamento de patologia a arteriosclerose é feita diferentemente (MOL, 2002, p. 35-36, grifo do autor, tradução nossa).

\footnotetext{
^ Financiamento: Este trabalho é financiado por ERC/FP7 (projeto “ALICE, espelhos estranhos, lições imprevistas" - agreement n. ${ }^{\circ}$ 269807), por Fundos FEDER através do Programa Operacional Factores de Competitividade (COMPETE)

$\star \star$ Endereço para correspondência: Colégio de S. Jerónimo. Apartado 3087. 3000-995. Coimbra, Portugal.E-mail: bsenamartins@gmail.com
}

No entanto, Mol faz notar que o facto de o corpo ser diferentemente constituído não implica a sua fragmentação; ele é mantido reunido, por exemplo, pelo modo como os diferentes departamentos dialogam na definição de uma decisão de tratamento:

A ontologia na prática médica está vinculada a um lugar e a uma situação específicos, num único edifício médico existem diferentes arterioscleroses. É um dos grandes milagres da vida hospitalar: existem diferentes arterioscleroses num hospital, mas apesar das diferenças elas estão ligadas. A arteriosclerose performada [enacted] é mais do que uma - mas menos do que muitas. O corpo múltiplo não é fragmentado, mesmo se é múltiplo, também se mantém junto (MOL, 2002, p. 55; tradução nossa).

A noção de corpo múltiplo que $\mathrm{Mol}$ oferece parece-me particularmente preciosa para pensar o modo como o corpo pode ser diferentemente percebido e significado sem que essas diferentes construções o pulverizem em muitos. Mobilizo as reflexões de $\mathrm{Mol}$ ao encontro de uma leitura que exprime o modo como o corpo e as suas diferenças são investidos de significado, de forma diversa, a partir de diferentes instâncias de produção de significado. Ganha relevância a recursividade entre o corpo físico e corpo social, de que nos fala Douglas (1973, p. 93; tradução nossa):

O corpo social condiciona o modo como o corpo físico é percebido. A experiência física do corpo, sempre modificada pelas categorias sociais porque é conhecido, suporta uma visão particular da sociedade. 
O lugar do corpo na crítica social das últimas décadas viria a ficar irremediavelmente marcado pela centralidade que este tema recebeu na obra de Michel Foucault, na qual o corpo surge como locus privilegiado de atuação das formas de poder que a modernidade consagrou, muito por relação com os processos de normalização que Foucault caraterísticos do poder moderno (FOUCAULT, 1961; $1975 ; 1980 ; 1994)$. Ao definir a norma e os imperativos normativos enquanto centro gravítico do conhecimento nas ciências da vida, Foucault reflete a influência do pensamento de Canguilhem, de que obra cabe relevar o livro Le Normal et le Patologique" (1984). Canguilhem inquire acerca da disseminação de uma distinção entre o normal e o patológico desde o surgimento dos termos em meados do século XVIII, até à sua estabilização como dogma científico no século XIX. Se é verdade que o anormal não é patológico, diz Canguilhem, o patológico emerge decisivamente como anormalidade. Em particular, Canguilhem analisa como a aceitação da diferenciação entre o normal e o patológico surge como produto da sua coimplicação ontológica com os territórios da biologia e da medicina.

É no mesmo sentido de Canguilhem que Herzlich (1991) vem defender que a medicina se deve à criação da ideia de norma alterada. Na verdade, desde esse tempo, a história dos corpos jamais se libertaria da consagração do modelo biomédico do corpo enquanto norma reguladora das práticas discursivas da medicina. Uma transformação nas configurações dos corpos cujo decisivo ponto de viragem Mirzoeff (1995, p. 45, tradução nossa) localiza no século XVIII:

Na segunda metade do século XVIII, a ciência médica começou a sustentar-se numa distinção entre os estados normais do corpo e as suas patologias, isto é as suas doenças e anormalidades.

Temos, portanto, uma radical transformação das constelações de sentido dos corpos, que assim deixam de estar ligados a uma conceção relativista do corpo - alheia aos processos de normalização — que nos acompanhou até ao século XVIII (MIRZOEFF, 1995), para passarem a serem imbuídos de sentido por relação noção biomédica de norma corporal, tida como uma regra natural.

\section{A Deficiência no ventre da modernidade}

A definição da deficiência enquanto idioma cultural eminentemente moderno liga-se, pois, a uma valorização do corpo como objeto de saberes e como elemento nas relações de poder ocorrida a partir do século XVII (FOUCAULT, 1994, p. 110). Interessa portanto analisar o papel que viria a ser desempenhado pela emergência de um paradigma biomédico na nossa sociedade.

Conforme afirma Foucault (1980, p. 109), a medicina constituiu-se com uma armadura científica sólida - desde logo por comparação com a psiquiatria - mas que se encontra, não obstante, igualmente imbuída nas estruturas sociais, forjando-se no seu discurso uma inédita relação entre o biológico e o político (FOUCAULT, 1994, p. 144). Assim o dispositivo biomédico é passível de ser interpretado como uma expressão particular da tecnologia do poder moderno constituída pelo conhecimento científico. Na verdade, a fulcral importância que Foucault confere ao corpo e ao conhecimento médico não é senão manifestação da centralidade que o autor atribui às formas de poder e enquadramentos de normalidade que acompanham o estabelecimento dos saberes da biomedicina, uma expressão da etnociência ocidental particularmente afeita a "produzir" realidade.

O corpo múltiplo de que falávamos, nesta aceção, faz-nos perceber de que modo a biomedicina moderna oferece apenas uma versão para definir a materialidade da deficiência ou a deficiência como materialidade. A naturalização da deficiência enquanto uma condição cujas implicações dizem respeito ao corpo físico é um processo de fechamento de sentido. Este fechamento é profundamente desafiado por perspetivas que nos mostram que as condições que chamos deficiência são diferentemente entendidas, sem uma relação com a dicotomia normal/ patológico, noutros momentos históricos ou em espaços culturais cujas leituras do corpo escapam à hegemonia dos valores biomédicos (STRIKER, 1999; INGSTAD; WHYTE, 1995; MARTINS, 2013).

Reconhecer um corpo cujos significados e implicações variam seja entre diferentes paradigmas culturais, seja pelo modo como convocam (e se inscrevem em) relações sociais proverbialmente dinâmicas, não significa recusar materialidade fenomenológica de uma condição como, por exemplo, uma cegueira, uma paraplegia ou de uma paralisia cerebral. Não nos instalamos no idealismo da desincorporação do significado conquanto a "espessura material" de uma cegueira - a sua implicação fenomenológica ao nível da experiência incorporada, a impossibilidade de ver - é aquilo que "mantém junto" o corpo múltiplo; é aquilo que nas palavras de Mol (2002, p. 55) o faz ser "mais do que um e menos que muitos". O privilégio da cegueira como ilustração argumentativa liga-se ao trabalho prévio que realizámos no intuito de comparar as representações culturais da cegueira em Portugal e em Moçambique (MARTINS, 2013). Se em Portugal identificámos a força constitutiva da ideia de deficiência para definir a cegueira, em termos medicalizados, como deficiência visual, em Moçambique confrontámo-nos com a hegemonia das interpretações sócio-espirituais, de tal modo que a cegueira ali tem muito mais a ver com as leituras que convocam espíritos, curandeiros e feitiços do que com qualquer ideia de normalidade biomédica e seus desvios. Encontrámos, pois, uma "diferença paradigmática" entre a cegueira entendida mormente como produto de feitiço - e de relações sócio-espirituais - e a cegueira naturalizada como deficiência visual (MARTINS, 2013).

A nomeação e interpretação das alterações e diferenças nos somata é sempre um processo eminentemente social; no limite — o forjado pela biomedicina moderna ainda que essa elaboração conduza a uma naturalização do sentido capaz de o subtrair das relações sociais que o geram. O reconhecimento da objetificação da deficiência modernidade ocidental, enquanto uma condição patológica por oposição a uma putativa normalidade funcional, recobre-se das mais profundas implicações para que se possam apreciar os constrangimentos que aí se inscre- 
veram nas possibilidades de inclusão social das pessoas nomeadas como "deficientes". A questão central que decorre da moderna invenção da deficiência prende-se, pois, com a "des-socialização" das suas implicações através de um ancoramento médico. Identificam-se os efeitos de um investimento cultural e político marcado pelos discursos e práticas da medicina, vocacionado a negligenciar as condições sociais mais amplas da vivência e a privilegiar os discursos de profissionais em detrimento da reflexividade das pessoas com deficiência.

Importa, pois, que nos confrontemos com a espessura de verdade da materialidade, por exemplo, do corpo de uma pessoa privada do sentido da visão. Ou seja, urge pulsar a tentação narrativa que a epistemologia moderna nos oferece para pensarmos o que modernamente foi feito da cegueira. Dirigimo-nos à instigante asserção de que sendo as culturas redes de significado que nos permitem conferir significado ao mundo, nós tanto as possuímos como somos possuídos por elas (HANNERZ, 1996, p. 58).

\section{Corpos e materializações}

Há, sem dúvida, um indisfarçável construtivismo no modo como acolho a deficiência enquanto um produto modernidade ocidental. No limite, este construtivismo permite esboçar um paralelismo com a análise que Foucault (1961) produz sobre a loucura na sua influente genealogia Folie et Déraison: Histoire da la Folie a l'Age Classique. A irmandade possível entre a identificação da loucura e a objetificação da deficiência resultará de uma analogia nas condições do seu nascimento ou da sua individualização epistemológica, à luz de uma economia de poder-saber distintamente moderna:

Eu tenho estudado a objetificação do sujeito através daquilo a que tenho chamado "práticas de separação". O sujeito é separado dentro dele ou em relação aos outros. Este processo objetifica-o. Os exemplos são os loucos e os sãos, os doentes e os saudáveis, os criminosos e os "bons rapazes" (FOUCAULT, 2003, p. 127, tradução nossa).

Estamos, pois, perante uma economia singular e prolixa, marcadamente filha da modernidade ocidental, de onde radica toda uma parafernália de práticas heterogéneas, "práticas de separação" através das quais doença é distinguida da saúde, a submissão à lei do crime, a loucura da sanidade, a ociosidade da incapacidade, a normalidade da deficiência, etc.

No entanto, é necessário determinar os termos da proximidade que, ancorados à deficiência, estabelecemos em relação ao papel constitutivo que Foucault confere às práticas discursivas, com base num posicionamento nominalista em que "os discursos produzem os objetos de que falam” (FOUCAULT, 1969, p. 67). Se é verdade que esta atitude epistemológica parece não ser demasiado problemática para uma categorização tão controversa como a da loucura, visibilizando o quão debatível é a relação da psicopatologia com as suas produções (FREUNDLIEB, 1994), a questão assume contornos diversos para a inegável materialidade corpórea que se liga à nomeação cultural de uma condição como, por exemplo, a cegueira. Confrontamo-nos aqui com uma inelutável tan- gibilidade corporal, que se liga ao modo como determinadas pessoas se encontram privadas do sentido da visão. Conforme assinala Judith Butler, importa reconhecer a instável relação do corpo com o idealismo linguístico do pós-estruturalismo. De facto, acredito ser possível referir que a cegueira foi inventada como deficiência visual. No entanto, a menção à cegueira não nos envia para uma qualquer pureza pré-moderna, uma vez que sempre esteve imbuída de valores particulares. Tampouco poderemos falar da cegueira sem estarmos vinculados aos termos em que ela foi modernamente entendida como uma deficiência. $\mathrm{O}$ que parece ser certo é que existe uma comunalidade corpórea, trans-histórica e trans-cultural, ligada àquilo a que alternada e sucessivamente se tem chamado cegueira e deficiência visual. Portanto, julgo relevante que procuremos pulsar as virtualidades e limites de uma epistemologia construtivista do corpo, centrados na relação que ela nos permite desenhar com a materialidade. Fazemo-lo contra uma tradição das ciências sociais caracterizada por perspetivas do corpo que, movendo-se nas exterioridades da "corpo carnal", reiteradamente negligenciaram o corpo vivido e a experiência incorporada; conforme sintetiza Almeida (1996, p.16) no seio de numa análise retrospetiva: "privilegiou-se a inscrição, negligenciou-se a incorporação".

A obra Bodies that Matter, de Butler (1993), numa evidente inspiração pós-estruturalista, oferece-nos uma portentosa reflexão em torno das relações entre a crítica social contemporânea - nascente das "ruínas do $\log o s$ " - e a materialidade dos corpos. Instigada a confrontar-se com a denúncia de que o corpo vem sido contemporaneamente acolhido na teoria social — e na sua própria obra — por epistemologias idealistas, marcadas de uma somatofobia e que, portanto, tendem a negar o corpo enquanto entidade material, Butler (1993, p. xi, tradução minha) propõe fixar-se no reconhecimento da realidade material do corpo:

Seguramente os corpos vivem e morrem, comem e dormem, sentem dor, prazer, suportam doença e violência; e esses factos, pode-se proclamar cepticamente, não podem ser desmobilizados como mera construção.

No entanto, Butler recolhe o significado profundo do seu próprio fracasso, isto é, a impossibilidade de se deter nas fronteiras dos corpos para os conhecer e compreender enquanto instâncias materiais. Ao procurar fixar-se nos estritos limites dos contornos dos corpos, Butler repetidamente era enviada para além deles. Concluiu então que os corpos não apenas tendem a indicar um mundo para além deles, mas esse movimento para fora dos seus limites mostra ser central para o que os corpos "são" (BUTLER, 1993, p. ix).

A autora coloca-nos perante o caráter incontornável da construção enquanto um "constrangimento constitutivo", sugerindo que os corpos só existem dentro de esquemas regulatórios que engendram a circunscrição da inteligibilidade cultural. Em particular, numa perspetiva que se nutre de uma leitura feminista, Butler dirige-se para um olhar inspetivo das elaborações pelas quais os corpos nos surgem demarcados pelos ideais regulatórios 
da diferença sexual. Aportamos numa incontornável cisão das configurações corpóreas que decorrem de uma matriz cultural patriarcal e heterossexista. O desafio que Butler coloca à sua empreitada analítica consiste em tentar conciliar uma perspetiva alimentada pela crítica feminista contemporânea, onde se nega a distinção entre sexo e género, com o reconhecimento da existência material dos corpos a que chamamos masculino e feminino. Assim, numa primeira instância, Butler recusa a versão do feminismo que, ao sustentar a diferença entre o género e sexo como o investimento do social sobre o natural, encosta o natural como aquilo que está antes da inteligibilidade. Butler assinala que o sexo que é referido como estando antes do género, numa eventual pureza corpórea é, ele próprio, um postulado elaborado na linguagem. Nesse sentido, ao assentirmos no caráter incontestável do sexo ou na sua materialidade, estamos sempre a conceder a alguma versão do sexo, a alguma versão da sua materialidade (BUTLER, 1993, p. 10); as diferenças corporais emergem, portanto, incontornavelmente ligadas aos jogos de linguagem em que ganham inteligibilidade, onde se constituem como existentes.

Se o corpo significado como sendo anterior à significação é um efeito da significação, então o estatuto representacional ou mimético da linguagem, que reivindica que os signos seguem os corpos como os seus espelhos necessários, não é de forma alguma mimético. Pelo contrário, é produtivo, constitutivo, poderíamos mesmo dizer performativo, na medida em que este ato significante delimita e estabelece os contornos do corpo que considera encontrar antes de qualquer e toda a significação (BUTLER, 1993, p. 10, tradução nossa).

Ao negar a distinção entre sexo e género, e ao entender a materialidade do sexo e da diferença sexual como produtos dos discursos e de critérios de inteligibilidade historicamente reformuláveis, Butler parece não se libertar de um proverbial nominalismo que contempla os corpos como meros produtos da linguagem. E se é verdade que a análise da autora não deixa espaço para que se contemplem aspetos mais fenomenológicos da experiência corpórea dos sujeitos, a riqueza da sua abordagem está no modo como a construção social das formações do corpo são descritos enquanto processos de "materialização". Ou seja, as elaborações culturais da modernidade ocidental por via das quais o sentido dos corpos nos é dado erigem-se como materializações que definem o que é a existência material de um corpo, as suas fronteiras e contornos, criando o efeito de uma superfície a que chamamos matéria. Portanto, reconhecer a materialização como uma forma particular de construção por que se define o que são os corpos, não corresponde à negação da materialidade dos corpos, mas sim à aceitação da indeterminação no modo como essa materialidade nos é dada. Como assente Mirzoeff (1995, p. 21, tradução nossa):

O corpo é o objeto de cuja materialidade mais certos estamos, mas o indefinível potencial dessa materialidade, inevitavelmente incompleta, permanece como uma constante fonte de ansiedade.
Assim como não há um sexo puro que preceda o género - a suposta elaboração cultural do sexo —, do mesmo modo inexiste uma materialidade pura do corpo, que embora não se resuma ao modo como nos aparece pela linguagem, também nunca lhe escapa completamente:

A linguagem e a materialidade estão inteiramente imbricadas uma na outra, quiasmáticas na sua interdependência, mas nunca colapsadas uma na outra, i.e., reduzidas uma à outra, e, ainda assim, uma nunca excede completamente a outra. Sempre já coimplicadas, sempre já excedendo uma à outra, a linguagem e a materialidade não são inteiramente idênticas nem inteiramente diferentes (BUTLER, 1993, p. 69 , tradução nossa).

Sabemos, pois, que existe uma materialidade dos corpos que escapa aos discursos que a definem, mas não podemos saber o que é essa materialidade sem aludirmos às formações de sentido em que ela se torna inteligível, aos constrangimentos constitutivos que lhe permitem existir para o significado no mesmo movimento em que elaboram o seu fechamento. Neste sentido, o reconhecimento de toda uma pletora de materialidades que associamos aos corpos, às suas diferenças, processos e funcionalidades, constitui, como afirma Butler, apropriando Jacques Lacan, uma citação das estruturas normativas que estende as relações de poder. Ou seja, a "materialização" pela qual a matéria do corpo adquire sentido, é entendida como uma prática de criação e reiteração, através da qual as relações de poderes e as lógicas de dominação se confirmam e reproduzem (BUTLER, 1993, p. 14; 15; 106-108). Butler recupera aqui a questão foucauldiana da imanência da formação dos sujeitos no poder, questionando em que medida a assunção do género masculino ou feminino se constitui como uma materialização que reifica os valores patriarcais e heterossexistas. A esta possibilidade, problemática quer para a constituição de subjetividades, quer para as lutas feministas, Butler opõe o vislumbre de itinerários pessoais e políticos que possam buscar resignificações e rearticulações partindo das categorias historicamente sedimentadas.

Em todo o caso, a perspetiva de Butler mostra-se instrutiva para uma leitura contextual da diferença corporal (ou das diferenças identificadas nos corpos) que se distancie de um idealismo antissomático, reconhecendo a materialidade dos corpos, ao mesmo tempo que assente na ideia de que essa materialidade nos é sempre dada dentro de formações discursivas - constrangimentos constitutivos, pois. Igualmente importante é a relação que os processos de materialização estabelecem com as relações de dominação, que se encontram constantemente atualizadas nas reiteradas demarcações com que as materialidades se identificam, reconhecem e nomeiam. A interpretação feminista de Butler concede prioridade a pulsar de que modo a hegemonia heterossexual se reproduz na identificação da diferença sexual das mulheres e dos homens. E, apesar dos interesses particulares de Butler, essa mesma leitura constitui-se um poderoso elemento heurístico na apreciação da objetifivação corporal das pessoas deficientes enquanto tal. 
As implicações e incidência da cegueira não são passíveis de se esgotar nas diferentes formas de objetificação cultural que lhe assistem. Assim, ainda que não nos envie já para as implicações fenomenológicas do corpo vivido, a interpretação de Butler permite-nos reconhecer a inegável materialidade dos corpos, reconfigurando a sua construção moderna como deficiência visual enquanto uma forma de "materialização".

A proposta de Butler ajuda-nos a reconfigurar a persuasão de deficiência construída/inventada pela razão moderna, sendo que essa elaboração cultural uma forma de "materialização" engendrada por referência à nascente hegemonia da normalidade. Esta precisão que nos convida a perceber como a deficiência foi biologicamente materializada mostra ser de fulcral importância por duas principais razões.

Primeiro, porque nos instiga a recusar a ideia de um corpo puro, a existência apriorista de uma deficiência e de uma condição patológica a ser mediada por interpretações culturais. Ou seja, tal como a negação da distinção entre o sexo e o género se erige contra a existência de um sexo puro antes da significação, consentindo que quando falamos desse sexo o fazemos sempre por referência a algum código de inteligibilidade, também a busca dos termos em que a deficiência foi definida como materialidade nos convoca para desvelarmos a versão de materialidade que a modernidade nos oferece acerca da cegueira. Portanto, o facto de a deficiência ter vindo a vigorar nas representações culturais dominantes, enquanto uma forma particular de patologia e um desvio em relação a um padrão de normalidade, não constitui uma invenção cultural que se erige perante a pura materialidade de uma privação sensorial, mas é o itinerário onde essa materialidade se constitui dominante para a modernidade ocidental.

Em segundo lugar, porque ao articularmos a constituição da materialidade de uma deficiência com aqueles que são traços estruturantes da epistemologia moderna ocidental dirigimo-nos a um ponto essencial para a análise que aqui se pretende. Refiro-me à capacidade do discurso positivista alegar a exatidão da representação na definição do natural, enquanto oposto à cultura, constituindo uma "materialização" do natural que, por isso, nega o que nela há de representação. Embora Judith Butler se tenha dirigido para os contornos da diferenciação sexual pelo privilégio de um enfoque da sua definição a partir da normatividade heterossexual, ${ }^{1}$ a leitura que a autora oferece abre caminho para que nos possamos dirigir ao reconhecimento daquilo que poderíamos designar por estratégias somatizantes. Isto é sugerido quando Butler (1993, p.30) afirma que, ao negarmos distinção entre sexo e género, recusamos a incontaminação cultural de um sexo posto antes do género, negando-se assim o "estatuto representacional ou mimético da linguagem". Butler aponta, pois, para um sexo que se constituiu como materialidade através de uma ênfase construída que cristaliza a representação tirando-a do discurso. Estamos perante uma representação que retira o corpo da representação ${ }^{1} \mathrm{~A}$ autora reconhece o que há de excludente nesta opção, assentindo na existência de outros regimes regulatórios que concorrem para os processos de definição e diferenciação corporal (cf. BUTLER, 1993, p. 17-18). ou, mais especificamente, uma materialização que constitui o corpo como materialidade, apartando-o da cultura pela linha divisória da cisão entre natureza e cultura.

Um corpo posto fora da representação é um corpo que se subtrai a questionamentos culturais mais amplos, acompanhando o modo como o domínio da natureza se remete para uma exterioridade à cultura. Fronteira que Merleau-Ponty (1999, p. 51) assim desmistifica:

É absurdo pretender que a natureza seja, mesmo que só em intenção, o objeto primeiro da nossa perceção: ela é muito posterior à experiência dos objetos culturais, ou antes, ela é um deles.

Neste sentido, a ênfase nas estratégias somatizantes (raciais, sexuais, relacionadas com as deficiências, etc.) permite-nos aceder a algo que Butler só aflorou marginalmente, a saber, a relação dos processos de naturalização corporal com a epistemologia moderna ocidental. Esta questão é tão mais central dado que se relaciona com a necessidade de reconhecer e desafiar a vocação da modernidade ocidental para o naturalismo e para o reducionismo biológico (GOOD, 1994, p. 166). Emergem assim dois vetores absolutamente constituintes das ciências modernas (e das ciências naturais em particular): a separação entre natureza e cultura pretende esquecer que "toda a natureza é humana" (SANTOS, 1996, p. 44), uma vez que foi a humanidade que inventou um tal conceito, bem como a crença na possibilidade de a ciência espelhar a realidade natural, representando-a tal como ela é. É este nexo epistemológico que importa reconhecer na leitura da "materialização" moderna da deficiência.

\section{Metáforas na carne}

A "materialização" da deficiência por referência à medicina e ao modelo biomédico do corpo, enquanto uma condição patológica, implica-se na persuasão de que essa "materialização" mais não é do que a recuperação das condições naturais, da realidade da cegueira, agora separada dos demónios, castigos, e dons e pecados com que durante tanto tempo formou um só corpo na história ocidental. Não havendo corpos puros, como nos mostrou Butler, a assunção moderna da materialidade da diferença corporal das pessoas cegas emerge ligada ao biopoder, à hegemonia da normalidade e à coeva "materialização" enquanto objeto biomédico. Portanto, a "contaminação" cultural por que se veio fixar a noção de deficiência passa inevitavelmente por reconhecer as formas de objetificação da medicina enquanto narrativas culturais sobre os corpos, suas características e diferenças. É exatamente contra a ideia de que biomedicina nos oferece uma análise científica e universal do corpo humano, que se deverá consagrar a medicina ocidental como uma etno-medicina, naquilo que é uma mais que evidente persuasão antipositivista:

A linguagem da medicina está longe de ser um simples espelho do mundo empírico. É uma rica linguagem cultural, ligada a uma versão altamente especializada da realidade e a um sistema de relações sociais, e que, quando empregue no tratamento médico, reúne profundas preocupações morais com as suas mais funções técnicas elementares (GOOD, 1994, p. 5, tradução nossa). 
Para esta ideia, onde se enfatiza a mediação cultural das descrições das realidades e dos corpos, vêm concorrendo perspetivas críticas investidas em tornar manifestas as metáforas de que dependem as representações de saúde e doença. Particularmente marcante é a análise que Sontag (1990) realizou em Illness as Metaphor e AIDS as a Metaphor, obra em que a autora explora as metáforas que permeiam as conceções detidas acerca de doenças como a tuberculose, o AIDS ou o cancro. Tornou-se notavelmente influente a análise que Sontag realizou acerca das metáforas militares presentes nas perceções populares e científicas da pandemia de AIDS - conforme assinala Bastos (2002), as metáforas militares tem uma história dentro da biomedicina que muito deve ao poder que estas ganharam na descrição dos mecanismos e agentes identificados ao nível da infeciologia. Construindo uma genealogia para o que outrora terão sido as conceções prevalentes nas leituras do cancro, Sontag visibiliza como as apreensões do AIDS vieram a ser imbuídas de uma oposição entre a doença, descrita como agente invasor o sistema imunitário como uma estrutura de defesa contra essas ofensivas. Mas, como aponta pertinentemente Good (1994, p. 45), sendo verdade que a análise de Sontag concorre para a asserção das doenças como representações culturais, o desejo acalentado pela autora de que a vivência da doença pudesse ser liberta do pensamento metafórico faz supor a possibilidade de uma compreensão do corpo e das suas condições purificada das metáforas.

Neste sentido, diz Good, Sontag reproduz o ideal iluminista de uma representação do corpo e da doença depurada das interferências culturais, sociais e políticas que os envolvem. É certo que podemos e devemos questionar os valores e representações que envolvem determinadas condições, deveremos inclusive apelar a outras elaborações metafóricas atentas às consequências da representação. No entanto, como bem denuncia Good, o intuito de elidir a cultura das apreensões da doença mais não é do que uma recapitulação das conceções positivistas acerca do conhecimento, onde se negligencia, numa primeira instância, o quão embebidas estão na matriz do paradigma cultural moderno conceções tão estruturantes como as de saúde e de doença.

Para esta mesma ideia nos conduz a instigante análise que Lakoff e Johnson (1999) realizam. Estes autores defendem que a cognição, o pensamento e a formação de conceitos são processos inerentemente marcados por uma razão metafórica. Deste modo, as metáforas não seriam apenas expressões linguísticas para veicular ideias, mas constituiriam a própria possibilidade de essas ideias serem pensadas. Chamando a atenção para a ténue linha que separa o literal e o metafórico, assim como para o restrito número de afirmações básicas que se poderão considerar literais, os autores reportam-nos para a assombrosa ubiquidade das metáforas em todas as conceções que elaboramos e partilhamos. As metáforas e a razão metafórica devem, pois, ser entendidas como algo estruturante do pensamento, constitutivas do conhecimento e do sentido que fazemos das coisas. Exemplificando, os autores discorrem acerca da inalienável relação que estabelecemos entre a ideia de amor e as metáforas que dele falam:

Será o conceito de amor independente das metáforas para o amor? A resposta é um ruidoso "Não!" As metáforas para o amor são significativamente constitutivas do nosso conceito de amor (LAKOFF; JOHNSON, 1999, p. 171172, tradução nossa).

Assim investidas, as metáforas não seriam apenas expressões poéticas de conceitos, sentimentos e relações com o mundo, mas seriam algo de resolutamente essencial às elaborações cognitivas e afetivas que mapeiam as vivências quotidianas, a filosofia e a ciência. Em suma, vivemos, pensamos e conhecemos através das metáforas, elas são estruturantes de qualquer ideia de verdade que possamos deter acerca do mundo e da realidade circundante. Esta leitura, que remete para as condições gerais da cognição e da produção de saber nos contextos de sentido partilhado, reforça a crítica de Good a Sontag, sedimentando a ideia de que a medicina, longe de se estabelecer como uma mera mimese da realidade dos corpos, toma parte de uma linguagem cultural a partir da qual a materialidade dos corpos é conhecida.

Sem traficar com qualquer tipo de idealismo linguístico ou somatofobia - o corpo é bem mais que um texto —, a argumentação que venho desenvolvendo instala-nos numa persuasão antipositivista, que se assume importante na medida em que nos insta a negar que a "verdade" da deficiência possa consistir ou resumir-se aos termos da sua objetificação biomédica e do reducionismo biológico.

A apreensão metonímica que a modernidade fez da deficiência por via da biomedicina, representa, assim, uma oportunidade perdida para a formação de uma sociedade mais inclusiva, um contexto organizado de relações e valores inspirado numa maior pluralidade de reflexividades. Sendo verdade que as pessoas com deficiência foram retiradas às hermenêuticas culturais de vocação cristã e metafísica que sobre elas se abatiam na pré-modernidade ocidental, o reconhecimento da sua condição enquanto um fenómeno corporal, natural, médico, está longe de se constituir como uma mera asserção daquilo que a deficiência é. A constituição da deficiência no natural por oposição histórica ao sobrenatural, além de a submeter a uma subalternização por relação a um corpo normal, constitui uma forma de localização que retira uma diferença do campo das representações culturais e da organização social, para a naturalizar enquanto inferioridade.

\section{Conclusão}

Neste texto propusemos um itinerário que fala do biopoder - atentando para as formas de regulação e normalização que a modernidade inaugurou gerando uma "sociedade somática" -; fala da hegemonia da normalidade - reconhecendo as topografias de desvio e subalternização resultantes da consagração de um modelo biomédico do corpo -; e fala das estratégias somatizantes - enfatizando o lugar de um reducionismo biológico que tende a 
naturalizar e medicalizar as relações sociais, representando o corpo como algo que está fora da representação, fora de questionamentos sociopolíticos mais amplos.

Analisando a deficiência como produto das formações de poder/conhecimento caracteristicamente modernas, a questão não é perceber como os discursos lesam os corpos, mas, conforme afirma Butler (1993, p. 224), compreender como certas construções os remetem para os limites das ontologias e dos esquemas de inteligibilidade existentes. Assim, o que se "fere" são as possibilidades para os sujeitos e as diferenças corporais que se lhes adscrevem se moverem de outro modo nos contextos de valores e de relações. Concretamente, trata-se de perceber em que medida a objetificação da deficiência contribui para cristalizar o lugar central de uma limitação sensorial, contribuindo para a invisibilização dos estigmas culturais que decorrem dessa mesma objetificação, e para que se mantenham intocadas as formas vigentes de hierarquização social.

É exatamente para um questionamento das formas da naturalização/somatização das hierarquias sociais que Boaventura Sousa Santos (2002) aponta no seio de uma crítica mais ampla da racionalidade moderna. $O$ autor identifica como elemento central da sua perplexidade a vigência na modernidade de uma razão, por si designada de indolente, que apresenta como central característica uma contração do presente e uma ampliação do futuro. Ou seja, identifica-se a vigência de um regime de razão que num mesmo momento adia o futuro, tornando longínquas as expectativas do agora, e contrai o presente, estreitando-o pelo desconhecimento e pela desqualificação da inesgotável experiência social existente no mundo. Estabelece-se neste quadro um nexo de impossibilidades em que a hegemonia se reproduz através do empobrecimento dos conhecimentos e experiências tidos como válidos no presente.

Assim, segundo Santos, uma das formas características centrais da razão indolente reside na sua vocação metonímica; e é exatamente a operacionalidade dessa razão metonímica que me interessa convocar para o seio da presente análise. Um dos traços centrais de uma tal racionalidade é uma obsessão pela totalidade e pela ordem, numa lógica em que o todo assume primordialidade perante as partes que o compõem:

A forma mais acabada de totalidade para a razão metonímica é a dicotomia, porque combina, do modo mais elegante, a simetria com a hierarquia. A simetria entre as partes é sempre uma relação horizontal que oculta uma relação vertical [...] todas as dicotomias sufragadas pela razão metonímica contêm uma hierarquia [...] (SANTOS, 2002, p. 242).

A linha desta reflexão desde logo nos reporta, pelas ressonâncias que oferece, para relação entre normalidade e deficiência, uma dicotomia moderna cuja simetria e a horizontalidade temos vindo a negar com base na ideia de uma hegemonia da normalidade. Mas, dado que a implicação central associada à vigência de uma razão metonímica é o desperdício da experiência que por ela não pode ser valorizada ou reconhecida, a sua identificação envia-nos para a centralidade que conferimos às condições históricas pelas quais as pessoas descritas como deficientes veem negada a sua reflexividade e intervenção social. Estamos perante as condições de produção de não existência de que nos fala Santos (2002, p. 246): "Há produção de não existência sempre que uma dada entidade é desqualificada e tornada invisível, ininteligível ou descartável de um modo irreversível”. Das lógicas que estão identificadas por Santos como produtoras do estreitamento de que padece a razão moderna - e que estão diretamente implicadas na produção de não-existência —, duas delas assomam com particular vigor na linha argumentativa que aqui venho desenvolvendo.

A primeira, diz-nos Santos (2002, p. 247), relaciona-se com "uma monocultura do saber e do rigor do saber". Aqui a produção de não existência decorre mormente do modo como a ciência moderna se estabeleceu como único critério de verdade, numa monocultura que opera, quer pela desqualificação de outras discursividades, quer pelas discursividades que se tornam impensáveis à luz dos constrangimentos constitutivos gerados no prestígio desse mesmo saber. Aspeto que nos reenvia para a medida em que as formas modernas de objetificação da cegueira foram embutidas numa noção de real, construída por saberes periciais, pouco conciliáveis com o surgimento e valorização de outras perspetivas. No fundo, outras realidades em cuja criação a autoria, experiência e reflexividade das pessoas cegas pudesse participar.

A segunda lógica de produção de não existência, assinalada por Santos, e cuja construção se mostra valiosa para este contexto, é a lógica da classificação social. Esta funda-se numa "monocultura da naturalização das diferenças" cujo aporte central é a "distribuição das populações por categorias que naturalizam as diferenças" (SANTOS, 2002, p. 247). O lugar desta lógica implica-se com a denunciada propensão da nossa epistemologia para o reducionismo biológico, bem como com as estratégias somatizantes que identificámos operarem na naturalização deficiência. O caráter mais insidioso desta forma de hierarquização reside no facto de a inscrição na fatalidade das diferenças corporais, em que assenta, conviver com o manifesto desejo da sua superação por via de estratégias normalizantes. É bem este o paradoxo central do projeto colonial do Ocidente, que Bhabha (1994, p. 83-84) "ambivalência da fantasia colonial": ao mesmo tempo que a legitimação da dominação colonial tinha por base uma missão civilizadora que pretendia resgatar o colonizado da sua inferioridade, postulava-se que essa inferioridade era insuperável na medida em que estava fatalmente inscrita numa corporalidade dita inferior. Entendo que o processo de normalização que se dirige às pessoas com deficiência, fundado numa classificação somatizante e numa hierarquia entre a normalidade (ausência de deficiência) e deficiência, emerge como uma resposta social que se funda num paradoxo análogo.

Alojando-se numa crítica à razão metonímica, identificada enquanto promotora de um empobrecimento da prolixidade das experiências do presente, Santos (2002, p. 252) vem propor que a "lógica da classificação so- 
cial", ancorada que está a uma "monocultura da naturalização das diferenças", possa dar lugar a uma "ecologia de reconhecimentos". Esta transição implica o resgate de perspetivas descredibilizadas, permitindo que a problematização da confluência entre hierarquia e diferença possa dar lugar a "diferenças iguais". Ou seja, implica reconhecer que há diferenças que não fazem sentido fora das hierarquias que consagraram a sua distintividade ${ }^{2}, \mathrm{e}$, sobretudo, importa sustentar a apologia de "uma ecologia de diferenças feita de reconhecimentos recíprocos" (SANTOS, 2002, p. 252). É, sem dúvida, para esta ecologia de reconhecimentos que a valorização da intervenção e da reflexividade das pessoas cegas nos envia; para um itinerário intimamente ligado a um aprofundamento democrático feito pela valorização plural de perspetivas, com ênfase para os grupos que têm sido reiteradamente encostados ao silêncio. Assim, procurando distanciar-nos das estratégias somatizantes características do pensamento moderno, colocamo-nos próximos do apregoado imperativo de se elaborar uma epistemologia dos conhecimentos e dos agentes ausentes (SANTOS, 2000, p. 229 232). Se é verdade os corpos e as suas diferenças jamais escapam às relações sociais que lhes dão significado, as linguagens da emancipação precisam urgentemente do contributo das pessoas que, ao serem marcadas pelo estigma da deficiência, estiveram longamente apartadas de uma presença condigna no espaço público. Nas vidas e nas "vozes" das pessoas com deficiência vivificam metáforas que se opõem às "velhas naturezas" da modernidade ocidental, essas metáforas configuram, cada vez mais, uma ecologia de "corpos não dóceis", os corpos materializados na árdua resistência aos guiões da normalidade.

\section{Referências}

ALMEIDA, M. V. D. Corpo presente: Antropologia do Corpo e da Incorporação. In: ALMEIDA, M. V. D. (Ed.). Corpo Presente: Treze Reflexões Antropológicas Sobre o Corpo. Oeiras: Celta, 1996. p. 1-22.

BHABHA, H. The Location of Culture. Londres: Routledge, 1994.

BAStOS, C. Ciência, Poder, Acção: as respostas à Sida. Lisboa: ICS, 2002.

BUTLER, J. Bodies That Matter: On the Discursive Limits of Sex. Nova Iorque: Routledge, 1993.

CANGUILHeM, G. Le Normal et le Patothologique. Paris: PUF, 1984

DOUGLAS, M. Natural Symbols: Explorations in Cosmology. Middlesex: Penguim Books, 1973.

FOUCAULT, M. Folie et Déraison: Histoire da la Folie a l'Age Classique. Paris: Libairie Plon, 1961.

FOUCAULT, M. L'arqueologie du Savoir. Paris: Gallimard, 1969.

FOUCAULT, M. Surveiller et Punir: Naissance de la Prison. Paris: Gallimard, 1975.

\footnotetext{
${ }^{2}$ Ainda que a sedimentação de uma categoria histórica produzida por uma hierarquizacão implique que os grupos em busca da transformação social muitas vezes tenham que partir da valorização dessa mesma categoria para poderem requalificá-la ou, eventualmente, elidi-la enquanto diferença.
}

Fractal, Rev. Psicol., v. 27 - n. 3, p. 264-271, 2015
FOUCAULT, M. Power/Knowledge: Selected Interviews and Other Writtings. Nova Iorque: Harvester Wheatsheaf, 1980.

FOUCAULT, M. História da sexualidade: a vontade de saber. Lisboa: Relógio de Água, 1994. v. 1.

FOUCAULT, M.; RABINOW, P.; ROSE, N. S. The essential Foucault: Selections From Essential Works of Foucault, 19541984. New York: New Press, 2003.

FREUNDLIEB, D. Foucault's Theory on Discourse and Human Agency. In: JONES, C.; POTER, R. (Ed.). Reassessing Foucault. Londres: Routledge, 1994. p. 152-180.

GOOD, B. Medicine, Rationality and Experience: an Anthropological Experience. Cambridge: University Press, 1994.

HANNERZ, U. Transnational Connections. Londres: Routledge, 1996.

HERZLICH, C. Medecine Moderne et Quête de Sens: la Maladie Signifiant Social. In: AUGÉ, M.; HERZLICH, C. (Ed.). Le Sens du Mal: Anthropologie, Histoire, Sociologie da la Maladie. Paris: Editions des Archives Contemporaines, 1991. p. 189-215.

INGSTAD, B.; WHYTE, S. (Ed.). Introduction, Disability and Culture: an Overview. Disability and Culture. University of California: Berkeley, 1995. p. 3-32.

LAKOFF, G.; JOHNSON, M. Philosophy in the Flesh: The Embodied Mind and its Challenge to Western Thought. Nova Iorque: Basic Books, 1999.

MARTINS, B. S. Sentido Sul: A Cegueira no Espírito do Lugar. Coimbra: Almedina, 2013

MERLEAU-PONTY, M. Fenomenologia da Percepção, São Paulo: Martins Fontes, 1999.

MIRZOEFF, N. Bodyscape: Art, Modernity and the Ideal Figure. Londres: Routledge, 1995.

MOL, A. The Body Multiple: Ontology in Medical Practice. Durham: Duke University, 2002.

SANTOS, B. D. S. Para uma Sociologia das Ausências e uma Sociologia das Emergências. Revista Crítica de Ciências Sociais, n. 63, p. 237-280, 2002.

SANTOS, B. D. S. Um Discurso Sobre as Ciências. Porto: Afrontamento, 1996.

SANTOS, B. D. S. Crítica da Razão Indolente: Contra o Desperdício da Experiência. Porto: Afrontamento, 2000.

SONTAG, S. Illness and Metaphor and Aids and Its Metaphors. Nova Iorque: Anchor Books, 1990.

STRIKER, H.-J. A History of Disability. Ann Arbor: University of Michigan Press, 1999.

Recebido em: 27 de setembro de 2015

Aceito em: 3 de outubro de 2015 